\title{
Nonalcoholic fatty liver disease and the risk of insulin-requiring gestational diabetes
}

\author{
Sang Youn You', Kyungdo Han², Seung-Hawn Lee ${ }^{3,4^{*}}$ and Mee Kyoung Kim
}

\begin{abstract}
Background: Nonalcoholic fatty liver disease (NAFLD) is one of the most common chronic liver diseases; however, there has been little research into its impact on gestational diabetes mellitus (GDM).

Methods: This study included 308,095 women registered in the Korean National Health Insurance Service database, who delivered between 2011 and 2015 and received a health examination within 52 weeks before pregnancy. Insulin-requiring GDM was defined as no insurance claims for diabetes mellitus and a fasting blood glucose level of $<126 \mathrm{mg} / \mathrm{dL}$ before pregnancy, and initiation of insulin treatment during pregnancy. A fatty liver index (FLI) was calculated using body mass index, waist circumference, and blood triglyceride and $\gamma$-glutamyl transferase levels. FLI scores $<30$ ruled out hepatic steatosis, while FLI scores $\geq 60$ indicated NAFLD.

Results: The prevalence of NAFLD was 0.8\% (2355/308,095) and 1984 (0.6\%) subjects developed insulin-requiring GDM. FLIs of 30-59 and $\geq 60$ were significantly associated with increased risk of insulin-requiring GDM (odds ratio [OR] 3.50; 95\% confidence interval [CI] 2.99-4.10; OR 4.19; 95\% Cl 3.37-5.23), respectively. Further exploration of the association of FLI with GDM across FLI decile categories revealed a steady increase in OR across the categories. The association was more prominent among those without metabolic syndrome.
\end{abstract}

Conclusion: NAFLD in women is an independent risk factor for insulin-requiring GDM.

\section{Introduction}

Nonalcoholic fatty liver disease (NAFLD) is defined as an increase in liver fat content, in the absence of any secondary cause of steatosis $[1,2]$. The prevalence of NAFLD increases in parallel with the increasing prevalence in obesity, metabolic syndrome (MetS), and type 2 diabetes mellitus (DM) [1,2]. Many longitudinal studies have shown that NAFLD is an independent risk factor for developing type 2 DM $[3,4]$. These different metabolic

\footnotetext{
*Correspondence: hwanx2@catholic.ac.kr; makung@catholic.ac.kr ${ }^{3}$ Division of Endocrinology and Metabolism, Department of Internal Medicine, Seoul St. Mary's Hospital, College of Medicine, The Catholic University of Korea, \#222 Banpo-daero, Seocho-gu, Seoul 06591, South Korea

${ }^{5}$ Division of Endocrinology and Metabolism, Department of Internal Medicine, College of Medicine, Yeouido St. Mary's Hospital, The Catholic University of Korea, \#10 63-ro, Yeongdeungpo-gu, Seoul 07345, South Korea

Full list of author information is available at the end of the article
}

diseases, NAFLD and type $2 \mathrm{DM}$, share a common metabolic dysfunction of insulin resistance. The insulinresistant fatty liver overproduces glucose and very-lowdensity lipoprotein [5]. This boosts mechanisms that lead to exhaustion of the pancreatic beta cell reserve, eventually leading to the development of DM [5]. Steatotic and inflamed liver secretes hepatokines such as fetuin-A, fetuin- $B$, angiopoietin-like proteins, fibroblast growth factor 21, and selenoprotein $\mathrm{P}$, which have endocrine functions at extrahepatic sites to cause insulin resistance and other adverse effects on glucose homeostasis [6]. Previous studies have shown an association between a history of gestational diabetes mellitus (GDM) and NAFLD in women $[7,8]$. We hypothesized that NAFLD before pregnancy could be a risk factor for the development of GDM.

GDM is a common international health problem in pregnant women, which can lead to adverse pregnancy

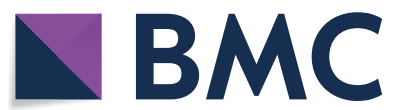

(c) The Author(s) 2021. Open Access This article is licensed under a Creative Commons Attribution 4.0 International License, which permits use, sharing, adaptation, distribution and reproduction in any medium or format, as long as you give appropriate credit to the original author(s) and the source, provide a link to the Creative Commons licence, and indicate if changes were made. The images or other third party material in this article are included in the article's Creative Commons licence, unless indicated otherwise in a credit line to the material. If material is not included in the article's Creative Commons licence and your intended use is not permitted by statutory regulation or exceeds the permitted use, you will need to obtain permission directly from the copyright holder. To view a copy of this licence, visit http://creativecommons.org/licenses/by/4.0/. The Creative Commons Public Domain Dedication waiver (http://creativecommons.org/publicdomain/zero/1.0/) applies to the data made available in this article, unless otherwise stated in a credit line to the data. 
outcomes [9]. As the number of women being diagnosed with GDM has increased in past decades, efforts are increasing to identify risk factors for GDM [9]. The severity of GDM is associated with maternal blood glucose levels that present a direct correlation with the risk of fetal involvement [10]. A need for insulin therapy might be a starting point for the characterization of patients with severe GDM related to greater difficulty in achieving glycemic control $[10,11]$. It is important to identify subjects who are at risk of developing severe GDM. Therefore, we conducted a large population-based study involving more than 300,000 pregnant women in Korea who received a health examination within 52 weeks before pregnancy to examine the prognostic significance of NAFLD before pregnancy for the risk of severe GDM.

\section{Methods}

\section{Data source and study population}

Using the Korean National Health Insurance Service (NHIS) database, we retrospectively recruited pregnant women from the population for the current study. The NHIS is managed by the government and is the sole insurer for health-care services with a coverage rate of approximately $97 \%$ of the population in the Republic of Korea. The NHIS database is available for populationbased cohort studies. Information on demographics, national health screening data, diagnosis statements defined by the International Classification of Disease $10^{\text {th }}$ revision (ICD-10) codes, medical treatments, and drug prescriptions is routinely collected and undergoes quality control before being released for research purposes [1214]. Enrollees in the NHIS are recommended to undergo a standardized medical examination at least every 2 years. This regular health examination includes anthropometric measurements, assessment of blood pressure, alcohol and smoking status, and physical activity in addition to laboratory tests after overnight fasting for serum glucose, total cholesterol, triglycerides, creatinine, liver function, and urinalysis. In this study, we searched the NHIS database to identify women who had delivered between 2011 and 2015 and estimated the date of conception as 280 days before the delivery date (Additional file 1: Figures S1, S2). Women who had undergone a health examination within 52 weeks before conception were selected $(\mathrm{n}=329,675)$. We excluded women who had DM before pregnancy $(n=2303)$ and had fasting blood glucose levels $\geq 126 \mathrm{mg} / \mathrm{dL}$ at the health examination $(\mathrm{n}=1278)$ or with missing data for at least one variable $(n=4570)$. Women with excessive alcohol use ( $\geq 30 \mathrm{~g} /$ day, $\mathrm{n}=6928$ ) and a history of viral hepatitis, autoimmune hepatitis or other forms of chronic liver disease $(n=6501)$ were also excluded from the analysis. Finally, 308,095 women were included in this study, which was approved by the
Institutional Review Board of Seoul St. Mary's Hospital, Seoul, The Catholic University of Korea (No. KC19ZESI0586). Informed consent was waived because we used deidentified and anonymous information in this study.

\section{Calculation of the fatty liver index}

We calculated the fatty liver index (FLI) according to the formula below, which incorporated levels of triglycerides and $\gamma$-glutamyl transferase (GGT), and body mass index (BMI) and waist circumference (WC) $[15,16]$ :

$$
\begin{aligned}
& \text { FLI }=\left(\exp \left[\text { Model }_{\mathrm{FLI}}\right]\right) /\left(1+\exp \left[\text { Model }_{\mathrm{FLI}}\right]\right) \times 100 \\
& \text { Model }_{\mathrm{FLI}}=(0.0953 \times \ln (\text { triglyceride }[\mathrm{mg} / \mathrm{dl}]) \\
&+\left(0.139 \times \mathrm{BMI}\left[\mathrm{kg} / \mathrm{m}^{2}\right]\right) \\
&+(0.718 \times \ln \mathrm{GGT}[\mathrm{IU} / \mathrm{l}]) \\
&+(0.053 \times \mathrm{WC}[\mathrm{cm}]) 15.745 .
\end{aligned}
$$

We classified the study population into three groups according to the FLI as follows [13, 14]: low-risk group, defined as $\mathrm{FLI}<30$; intermediate-risk group, defined as $30 \leq \mathrm{FLI}<60$; and high-risk group, defined as $\mathrm{FLI} \geq 60$. FLI scores $<30$ ruled out hepatic steatosis, while FLI $\geq 60$ indicated NAFLD $[15,16]$.

\section{Measurements and definitions}

We defined obesity as a $B M I \geq 25.0 \mathrm{~kg} / \mathrm{m}^{2}$, according to the World Health Organization Western Pacific Region guideline [17]. Abdominal obesity was defined as a $W C \geq 85 \mathrm{~cm}$ [18]. Information on smoking status was obtained from a self-reported health survey questionnaire (current smoker, defined as those who had smoked over 5 packs during their lifetime and continued to smoke). Drinking status was defined as mild ( $<30 \mathrm{~g} /$ day) or nondrinking. Regular exercise was defined as moderate physical activity performed for more than $20 \mathrm{~min}$ at least 3 times per week or strenuous physical activity performed more than $30 \mathrm{~min}$ at least 5 times per week. We dichotomized household income levels at the lowest 25\% for the analysis.

Insulin-requiring GDM was defined as having no history of previous diabetes and receiving a prescription for insulin during the pregnancy. Participants with nonGDM or GDM without insulin treatment were treated as the control group.

\section{Statistical analysis}

Continuous variables are presented as mean \pm standard deviation (SD) and median (25-75\%), while the categorical variables are presented as $\mathrm{n}$ (\%) for each group. The participants were classified into three groups according to cut-off scores of FLI (30 and 60). 
We performed one-way analyses of variance (ANOVA) or Chi-square test, as appropriate to compare each group. Multiple logistic regression analysis was performed to obtain odds ratios (ORs) and 95\% confidence intervals (CIs) for GDM. The multivariable-adjusted models used in the analysis were as follows: model 1 was adjusted for age; model 2 was adjusted further for socioeconomic status (smoking, alcohol drinking, regular exercise, and income status), fasting blood glucose, and dyslipidemia; and model 3 was adjusted further for family history of diabetes. The potential modification effect caused by age, smoking, hypertension, dyslipidemia, and MetS was identified through a stratified analysis and interaction testing using the likelihoodratio test. We also performed the same analyses according to the FLI components (BMI, WC, triglycerides, and GGT highest quartile). SAS software (version 9.4;
SAS Institute, Cary, NC, USA) was used for the analyses and a $P$ value $<0.05$ was considered to indicate statistical significance.

\section{Results \\ Clinical characteristics of the study population before pregnancy}

The prepregnancy characteristics of the study population according to their baseline FLI categories are shown in Table 1 . In this population, 2355 subjects $(0.8 \%)$ were identified as having NAFLD (FLI scores $\geq 60$ ), while 7265 subjects $(8.7 \%)$ had a FLI score of $30-59$. Subjects with FLI scores $\geq 60$ were older, more likely to be current smokers and had a lower income (lower 25\%) than subjects with a FLI score $<30$. Subjects with FLI scores $\geq 60$ were more obese and had a higher prevalence of MetS.

Table 1 Clinical characteristics of the study subjects before pregnancy according to fatty liver index score category

\begin{tabular}{|c|c|c|c|}
\hline & \multicolumn{3}{|c|}{ Fatty liver index score } \\
\hline & $<30$ & $30-59$ & $\geq 60$ \\
\hline N & 298,475 & 7265 & 2355 \\
\hline Age (years) & $29.6 \pm 3.6$ & $31.1 \pm 4.4$ & $31.3 \pm 4.2$ \\
\hline$\geq 35$ years & $25,232(8.5)$ & $1370(18.9)$ & $467(19.8)$ \\
\hline Current smoker & $9867(3.3)$ & $688(9.5)$ & $319(13.6)$ \\
\hline Mild alcohol drinker & $144,475(48.4)$ & $3986(54.9)$ & $1312(55.7)$ \\
\hline Regular Exercise & $31,079(10.41)$ & $932(12.83)$ & $303(12.87)$ \\
\hline Income (lower 25\%) & $58,363(19.55)$ & $2131(29.33)$ & $781(33.16)$ \\
\hline Family history of DM & $28,016(13.0)$ & $1060(20.3)$ & $345(19.9)$ \\
\hline $\mathrm{BMI}\left(\mathrm{kg} / \mathrm{m}^{2}\right)$ & $20.5 \pm 2.3$ & $27.5 \pm 2.8$ & $31.5 \pm 3.6$ \\
\hline$<18.5$ & $52,986(17.8)$ & $3(0.04)$ & $1(0.04)$ \\
\hline $18.5-22.9$ & $204,030(68.4)$ & $378(5.2)$ & $21(0.9)$ \\
\hline $23-24.9$ & $27,633(9.3)$ & $963(13.3)$ & $39(1.7)$ \\
\hline $25-29.9$ & $13,498(4.5)$ & $4528(62.3)$ & $718(30.5)$ \\
\hline$\geq 30$ & $328(0.1)$ & $1393(19.2)$ & $1576(66.9)$ \\
\hline Waist circumferences (cm) & $68.7 \pm 6.2$ & $84.9 \pm 6.5$ & $93.8 \pm 8.0$ \\
\hline Triglyceride (mg/dL) & $66.9(66.8-67.0)$ & $137.8(136.4-139.3)$ & $172.6(169.3-176.0)$ \\
\hline GGT (IU/L) & $15.1(15.0-15.1)$ & $28.7(28.4-29.1)$ & $40.3(39.4-41.6)$ \\
\hline $\mathrm{FBG}(\mathrm{mg} / \mathrm{dL})$ & $87.1 \pm 9.0$ & $92.3 \pm 10.5$ & $94.7 \pm 11.3$ \\
\hline $\mathrm{TC}(\mathrm{mg} / \mathrm{dL})$ & $176.32 \pm 28.33$ & $197.88 \pm 33.73$ & $205.89 \pm 35.29$ \\
\hline AST (IU/L) & $14.0(14.0-14.1)$ & $23.3(23.0-23.6)$ & $32.4(31.6-33.2)$ \\
\hline $\operatorname{ALT}(I U / L)$ & $19.2(19.2-19.3)$ & $22.6(22.4-22.7)$ & $27.1(26.6-27.5)$ \\
\hline Systolic BP (mmHg) & $109.64 \pm 10.55$ & $118.68 \pm 11.89$ & $124.09 \pm 12.91$ \\
\hline Diastolic BP (mmHg) & $68.97 \pm 7.94$ & $74.91 \pm 8.77$ & $78.7 \pm 9.5$ \\
\hline Hypertension (yes) & $3102(1.0)$ & $524(7.2)$ & $349(14.8)$ \\
\hline Metabolic syndrome (yes) & $1739(0.6)$ & $1691(23.3)$ & $1374(58.3)$ \\
\hline
\end{tabular}

Data are expressed as the mean $\pm S D$, median (25-75\%), or $n(\%)$. P-values for the trend were $<0.0001$ for all variables because of the large size of the study population AST: aspartate transaminase; ALT: alanine transaminase; BMI: body mass index; BP: blood pressure; DM: diabetes mellitus; FBG: fasting blood glucose; GGT: gammaglutamyl transferase; TC: total cholesterol 


\section{Risk of insulin-requiring GDM according to the FLI}

There were $1,984(0.6 \%)$ women with GDM who received insulin therapy. Compared to subjects with FLI scores $<30$, the age-adjusted ORs for subjects with FLI 30-59 and FLI $\geq 60$ were 5.70 (95\% CI 4.98-6.53) and 9.96 (95\% CI 8.35-11.90) for insulin-requiring GDM, respectively (Table 2). These associations persisted after further adjustment for smoking, alcohol drinking, regular exercise, income status, fasting blood glucose, and dyslipidemia (model 2). The multivariable-adjusted ORs for subjects with FLI scores $30-59$ and $\geq 60$ were 3.53 (95\%

Table 2 Incidence rate and adjusted odd ratios (95\% confidence intervals) for the risk of insulin-requiring gestational diabetes by fatty liver index and each component of fatty liver index

\begin{tabular}{|c|c|c|c|c|c|}
\hline & Events (n) & Incidence rate* & Model 1 & Model 2 & Model 3 \\
\hline \multicolumn{6}{|c|}{ Fatty liver index } \\
\hline$<30$ & 1570 & 5.3 & 1 (Ref.) & 1 (Ref.) & 1 (Ref.) \\
\hline $30-59$ & 267 & 36.8 & $5.70(4.98,6.53)$ & $3.53(3.06,4.07)$ & $3.50(2.99,4.10)$ \\
\hline$\geq 60$ & 147 & 62.4 & $9.96(8.35,11.90)$ & $4.83(3.99,5.84)$ & $4.19(3.37,5.23)$ \\
\hline \multicolumn{6}{|c|}{ Body mass index $\geq 25 \mathrm{~kg} / \mathrm{m}^{2}$} \\
\hline No & 1413 & 4.9 & 1 (Ref.) & 1 (Ref.) & 1 (Ref.) \\
\hline Yes & 571 & 25.9 & $4.52(4.09,5.00)$ & $3.14(2.83,3.49)$ & $3.01(2.67,3.39)$ \\
\hline \multicolumn{6}{|c|}{ Waist circumference $\geq 85 \mathrm{~cm}$} \\
\hline No & 1676 & 5.6 & 1 (Ref.) & 1 (Ref.) & 1 (Ref.) \\
\hline Yes & 308 & 29.6 & $4.45(3.92,5.04)$ & $2.89(2.54,3.29)$ & $2.85(2.46,3.30)$ \\
\hline \multicolumn{6}{|c|}{ Triglyceride $\geq 150 \mathrm{mg} / \mathrm{dl}$ or lipid lowering treatment } \\
\hline No & 1584 & 5.4 & 1 (Ref.) & 1 (Ref.) & 1 (Ref.) \\
\hline Yes & 400 & 27.6 & $4.30(3.84,4.81)$ & $2.82(2.50,3.18)$ & $2.79(2.44,3.20)$ \\
\hline \multicolumn{6}{|c|}{ Gamma-glutamyl transferase (GGT) highest quartile, $\geq 18 \mathrm{IU} / \mathrm{L}$} \\
\hline No & 1007 & 4.3 & 1 (Ref.) & 1 (Ref.) & 1 (Ref.) \\
\hline Yes & 977 & 12.9 & $2.78(2.54,3.04)$ & $2.19(2.00,2.40)$ & $2.22(2.00,2.47)$ \\
\hline
\end{tabular}

*Per 1000 person-years

Model 1: Adjusted for age

Model 2: Adjusted for age, smoking, alcohol drinking, regular exercise, income status, fasting blood glucose, and dyslipidemia

Model 3: Adjusted for model $2+$ family history of diabetes

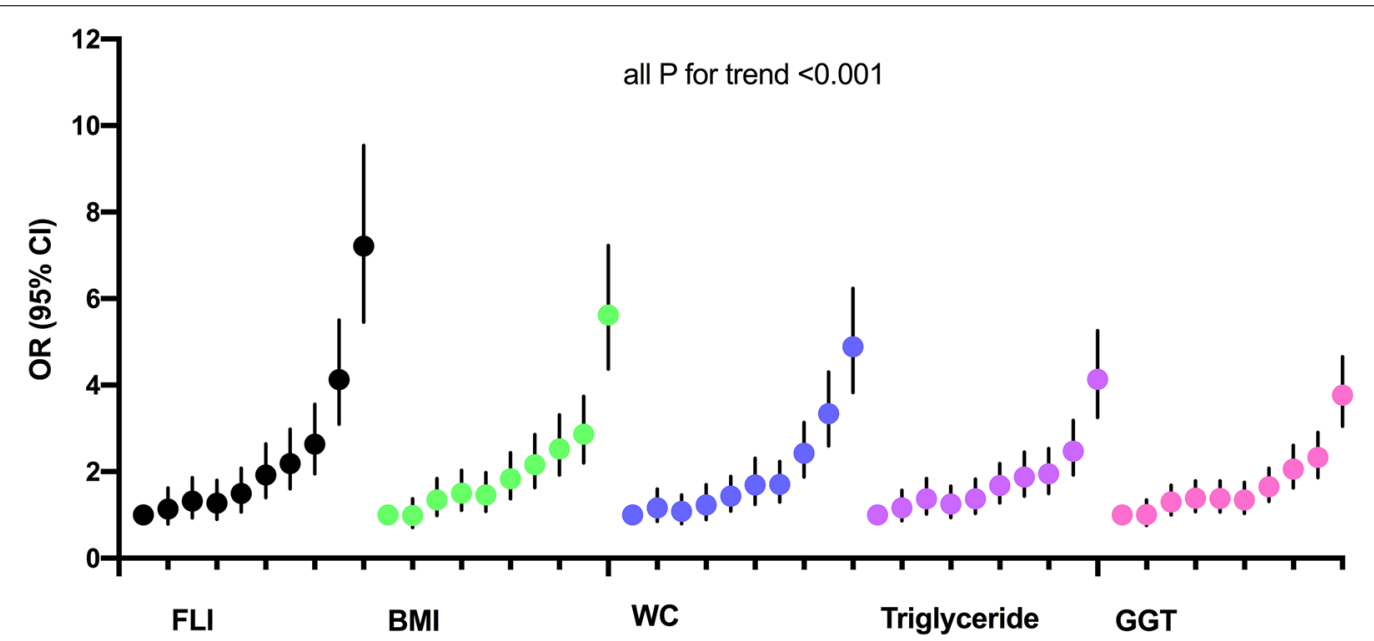

Fig. 1 Adjusted odd ratios and 95\% confidence intervals of insulin-requiring gestational diabetes by deciles of fatty liver index score and deciles of each component of the fatty liver index. Adjusted for age, smoking, alcohol drinking, regular exercise, income status, fasting blood glucose, and dyslipidemia 
CI 3.06-4.07) and 4.83 (95\% CI 3.99-5.84) for insulinrequiring GDM, respectively.

Further exploration of the association of FLI with GDM across FLI decile categories revealed a steady increase in OR across the categories (Fig. 1). Women within the 10th decile of FLI scores $(\mathrm{D} 10>12.5)$ were at greatest risk with a $622 \%$ increase in risk (OR 7.22; 95\% CI 5.46-9.54), compared with those with FLI scores in D1 (D1<1.3).

Individual components of the FLI were also associated with the risk of insulin-requiring GDM (Table 2, Fig. 1). However, these ORs were not stronger than the ORs between FLI and GDM (Fig. 1).

\section{Subgroup analyses by age, smoking, hypertension, dyslipidemia, and MetS}

We performed subgroup analyses according to age, smoking, absence or presence of hypertension, dyslipidemia, and MetS (Table 3). In all subgroups, the ORs of insulin-requiring GDM displayed an increasing trend as the FLI category increased. However, two subgroup analyses according to age and MetS displayed significant differences in ORs of insulin-requiring GDM ( $P$ values for interaction were 0.03 and $<0.001$, respectively). Higher adjusted ORs for insulin-requiring GDM were observed in the younger-aged (age $<35$ years) and nonMetS groups. When compared with subjects having FLI scores $<30$ and without MetS, having a FLI score $\geq 60$ without MetS was associated with a 3.5-fold increased risk of insulin-requiring GDM (OR 3.50; 95\% CI 2.415.09). Compared with subjects with a FLI score $<30$ and MetS, having a FLI $\geq 60$ and MetS was associated with a 2.1-fold increased risk of insulin-requiring GDM (OR 2.09; 95\% CI 1.53-2.86). These findings suggest that the utility of the FLI as a risk factor for GDM may be more valid in these subpopulations.
In additional sensitivity analyses, with the combination of FLI category and MetS status as a composite exposure variable, the risk of GDM was compared to subjects having FLI scores $<30$ and without MetS (reference group). Women having a FLI score $\geq 60$ and MetS were at the greatest risk of insulin-requiring GDM (Additional file 1: Figure S3).

\section{Discussion}

In this study, we demonstrated that the presence of NAFLD before pregnancy was associated with an increased risk of insulin-requiring GDM. We identified a stronger association among women without MetS before pregnancy, which supports the hypothesis that NAFLD is an independent risk factor for GDM, regardless of MetS status.

Our results are consistent with the findings of previous studies that demonstrated an association between NAFLD and GDM. A recent cohort study in a population of Korean pregnant women who visited two hospitals in Korea for prenatal care investigated whether the presence of NAFLD in the first trimester was a risk factor for GDM in mid-gestation [19]. In this population, $5.3 \%$ of all subjects had FLI scores $\geq 60$ [19], while in our study, only $0.8 \%$ had FLI scores $\geq 60$. The previous study's participants were composed of individuals who visited the two hospitals (secondary-level or university hospital) for prenatal care before 14 weeks of gestation [19]. Pregnant women attending secondary-level or university hospitals may have more risk factors than women attending primary hospitals. The differences in the prevalence of NAFLD appear to be related to differences in the population studied and different timing of NAFLD assessment (10-14 weeks of gestation vs. pre-pregnancy). Our study enrolled a large population representing $>300,000$

Table 3 Adjusted odd ratios (95\% confidence intervals) of insulin-requiring gestational diabetes by fatty liver index score category in subgroups according to age, smoking, hypertension, dyslipidemia, and metabolic syndrome

\begin{tabular}{|c|c|c|c|c|c|}
\hline & \multirow[t]{2}{*}{ Subgroup } & \multicolumn{3}{|c|}{ Fatty liver index } & \multirow[t]{2}{*}{$P$ for interaction } \\
\hline & & $<30$ & $30-59$ & $\geq 60$ & \\
\hline \multirow[t]{2}{*}{ Age } & $<35$ & 1 (Ref.) & $3.85(3.26,4.56)$ & $5.06(4.02,6.38)$ & 0.03 \\
\hline & $\geq 35$ & 1 (Ref.) & $2.92(2.26,3.78)$ & $4.28(3.06,5.99)$ & \\
\hline \multirow[t]{2}{*}{ Smoker } & No & 1 (Ref.) & $3.59(3.08,4.17)$ & $4.76(3.86,5.86)$ & 0.78 \\
\hline & Yes & 1 (Ref.) & $3.23(2.13,4.90)$ & $5.19(3.19,8.43)$ & \\
\hline \multirow[t]{2}{*}{ Hypertension } & No & 1 (Ref.) & $3.53(3.04,4.09)$ & $4.83(3.93,5.94)$ & 0.72 \\
\hline & Yes & 1 (Ref.) & $3.16(1.78,5.58)$ & $4.49(2.50,8.08)$ & \\
\hline \multirow[t]{2}{*}{ Dyslipidemia } & No & 1 (Ref.) & $3.38(2.89,3.94)$ & $5.20(4.22,6.41)$ & 0.14 \\
\hline & Yes & 1 (Ref.) & $4.31(2.99,6.20)$ & $3.95(2.52,6.20)$ & \\
\hline \multirow[t]{2}{*}{ Metabolic syndrome } & No & 1 (Ref.) & $3.19(2.67,3.81)$ & $3.50(2.41,5.09)$ & $<0.001$ \\
\hline & Yes & 1 (Ref.) & $1.62(1.19,2.19)$ & $2.09(1.53,2.86)$ & \\
\hline
\end{tabular}

Adjusted for age, smoking, alcohol drinking, regular exercise, income status, fasting blood glucose, and dyslipidemia 
deliveries. Because of the national health insurance coverage, almost all pregnant women in Korea undergo GDM screening and treatment during pregnancy; therefore, our findings reflect 'real-world' data, on a national scale, regarding the impact of pre-pregnancy NAFLD on the risk of GDM in Korean women.

Previous studies of the association between NAFLD and the risk of GDM did not consider the MetS status of the subjects $[7,19,20]$. However, a number of studies have looked into the association of GDM and components of the MetS [20, 21]. Hagström et al. [20] reported that the effect of NAFLD on the risks of preeclampsia and GDM was primarily seen in women with a BMI $<30 \mathrm{~kg} /$ $\mathrm{m}^{2}$. NAFLD did not influence any adverse outcomes of pregnancy among women with a BMI of $\geq 30$ [20]. A recent study demonstrated that a high FLI category is associated with an increased risk of the incidence of type $2 \mathrm{DM}$ in men without MetS [21]. In our study, we also identified that the association was stronger among women without MetS before pregnancy, suggesting that among women with MetS, which represents a cluster of risk factors for diabetes, a high FLI has less impact on the risk of GDM.

We discovered that the FLI was associated with risk of GDM in a dose-dependent manner. Comparison of risk using the FLI 1st decile as a reference revealed a steady increase in risk across FLI categories. The FLI is a multivariate model used to estimate fat accumulation in the liver and has been validated in multiple model systems [22]. Given that sonographic estimation of fatty liver is largely subjective and examiner-dependent, the observation that the FLI is associated with the risk of GDM reinforces our understanding of the clinical significance of NAFLD in pregnancy. The optimal cut-off point of the FLI for diagnosing NAFLD was 30 in middle-aged Chinese subjects [23]. In our study population, the 10th decile range of FLI was above 12.5. According to a study conducted in Taiwan, for men, the optimal cut-off scores are an $\mathrm{FLI}<25$ to rule out and $\mathrm{FLI} \geq 35$ to rule in sonographic fatty liver [24]. For women, a FLI $<10$ for exclusion and FLI $\geq 20$ for inclusion of fatty liver were nominated [24]. Due to variations in ethnicity, and dietary and environmental factors, the cut-off for WC and BMI is different for Asian people. Therefore, the FLI needs to be validated when used in different populations and cut off values for the FLI (30 and 60) should be rebalanced for appropriate application in women of childbearing age.

The current study had some limitations that warrant discussion. First, we only used the FLI to diagnose NAFLD and did not use histological examination and/ or liver ultrasound. Liver biopsy is the gold standard for diagnosis and staging of NAFLD, but it cannot be applied to population-based studies because of its highly invasiveness. Liver ultrasonography is not included in national health screening due to the lack of cost-effectiveness of mass screening.

Furthermore, liver ultrasonography is known to be a weak diagnostic tool for NAFLD, especially in the lower range $(<10 \sim 15 \%)$ of hepatic steatosis [25]. Second, there is currently little research to verify the validity of the FLI in the Korean population. One study reported that the area under the receiver-operator characteristic curve of FLI in Korean subjects is 0.86 , which is a relatively high level [16]. Third, we did not have data on transient elastography (TE) or acoustic radiation force impulse (ARFI). TE or ARFI data to evaluate liver fibrosis in patients with NAFLD could be helpful in understanding the correlation between the degree of fibrosis or severity of steatosis and the development of GDM. It was recently reported that elevated gamma-glutamyl transferase $(\geq 18 \mathrm{U} / \mathrm{L})$, and alanine aminotransferase $(\geq 17 \mathrm{U} / \mathrm{L})$ or elevation of both liver enzyme levels before pregnancy were independent risk factors for GDM in a subsequent pregnancy [26]. Fourth, we did not study data on insulin resistance such as HOMAIR (Homeostatic Model Assessment for Insulin Resistance), since it is difficult to conduct these tests for all participants in a mass screening program. Finally, the current study consisted of a Korean population only; therefore, these findings may not be able to be generalized to other ethnicities.

In the current study, the OR $(95 \% \mathrm{CI})$ of NAFLD for GDM was $4.83(3.99,5.84)$, implying that NAFLD should be considered a major risk factor for the development of GDM. We found a stronger association among women without MetS before pregnancy, which supports the hypothesis that NAFLD is an independent risk factor for GDM, regardless of MetS status. Early identification of women with NAFLD is important and more intensive screening and preventive strategies are needed for this subpopulation.

\section{Abbreviations}

BMI: Body mass index; FLI: Fatty liver index; GDM: Gestational diabetes mellitus; GGT: y-Glutamyl transferase; MetS: Metabolic syndrome; NAFLD: Nonalcoholic fatty liver disease; NHIS: National Health Insurance System; WC: Waist circumference.

\section{Supplementary Information}

The online version contains supplementary material available at https://doi. org/10.1186/s13098-021-00710-y.

Additional file 1: Figure S1. Flowchart of the study population. Figure S2. Timeline for the Study data collection. Figure S3. Adjusted odd ratios (95\% confidence intervals) of insulin-requiring gestational diabetes 
according to the presence of metabolic syndrome (MetS) and fatty liver index (FLI) category. Subjects with a FLI $<30$ and no MetS were analyzed as a reference group. Adjusted for age, smoking, alcohol drinking, regular exercise, income status, fasting blood glucose, and dyslipidemia.

\section{Acknowledgements}

This study was performed using the database from the National Health Insurance System (NHIS-2020-1-113), and the results do not necessarily represent the opinion of the National Health Insurance Corporation.

\section{Authors' contributions}

MKK, KDH, and SHL designed the study. KDH performed a statistical analysis. MKK and SHL take full responsibility for the accuracy of the data presented and analysed in this article. SYY wrote the manuscript and MKK, KDH and SHL edited the manuscript and contributed to discussion. All authors read and approved the final manuscript.

\section{Funding}

This study was supported by the research fund of Seoul St. Mary's Hospital, The Catholic University of Korea. This work was supported in part by the National Research Foundation of Korea Grant funded by the Korean Government (NRF-2020R1F1A1049539). The funders of the study had no role in study design, data collection, data analysis, data interpretation, or writing of the report.

\section{Availability of data and materials}

The datasets used and/or analyzed in the current study are available from the corresponding author upon reasonable request.

\section{Declarations}

\section{Ethics approval and consent to participate}

This study was approved by the Institutional Review Board of Seoul St. Mary's Hospital, Seoul, The Catholic University of Korea (No. KC19ZESI0586). Anonymous and deidentified information was used for analysis and, therefore, informed consent was not obtained.

\section{Consent for publication}

Not applicable.

\section{Competing interests}

The authors declare that they have no competing interests.

\section{Author details}

${ }^{1}$ College of Medicine, The Catholic University of Korea, Seoul 06591, South Korea. ${ }^{2}$ Department of Statistics and Actuarial Science, Soongsil University, Seoul 06978, South Korea. ${ }^{3}$ Division of Endocrinology and Metabolism, Department of Internal Medicine, Seoul St. Mary's Hospital, College of Medicine, The Catholic University of Korea, \#222 Banpo-daero, Seocho-gu, Seoul 06591, South Korea. ${ }^{4}$ Department of Medical Informatics, College of Medicine, The Catholic University of Korea, Seoul 06591, South Korea. ${ }^{5}$ Division of Endocrinology and Metabolism, Department of Internal Medicine, College of Medicine, Yeouido St. Mary's Hospital, The Catholic University of Korea, \#10 63-ro, Yeongdeungpo-gu, Seoul 07345, South Korea.

\section{Received: 11 May 2021 Accepted: 14 August 2021}

Published online: 26 August 2021

\section{References}

1. Rhee EJ. Nonalcoholic fatty liver disease and diabetes: an epidemiological oerspective. Endocrinol Metab. 2019:34:226-33.

2. Godoy-Matos AF, Silva Júnior WS, Valerio CM. NAFLD as a continuum: from obesity to metabolic syndrome and diabetes. Diabetol Metab Syndr. 2020;12:60.
3. Kotronen A, Laaksonen MA, Heliövaara M, Reunanen A, Tuomilehto J, Yki-Järvinen H, Peltonen M, Knekt P. Fatty liver score and 15-year incidence of type 2 diabetes. Hepatol Int. 2013;7:610-21.

4. Bae JC, Rhee EJ, Lee WY, Park SE, Park CY, Oh KW, Park SW, Kim SW. Combined effect of nonalcoholic fatty liver disease and impaired fasting glucose on the development of type 2 diabetes: a 4-year retrospective longitudinal study. Diabetes Care. 2011;34:727-9.

5. Valenti L, Bugianesi E, Pajvani U, Targher G. Nonalcoholic fatty liver disease: cause or consequence of type 2 diabetes? Liver Int. 2016:36:1563-79.

6. Targher G, Byrne CD. Clinical review: nonalcoholic fatty liver disease: a novel cardiometabolic risk factor for type 2 diabetes and its complications. J Clin Endocrinol Metab. 2013;98:483-95.

7. Ajmera VH, Gunderson EP, VanWagner LB, Lewis CE, Carr JJ, Terrault NA. Gestational diabetes mellitus is strongly associated with non-alcoholic fatty liver disease. Am J Gastroenterol. 2016;111:658-64.

8. Foghsgaard S, Andreasen C, Vedtofte L, Andersen ES, Bahne E, Strandberg C, Buhl T, Holst JJ, Svare JA, Clausen TD, Mathiesen ER, Damm P, Gluud $\mathrm{LL}$, Knop FK, Vilsbø\|l T. Nonalcoholic fatty liver disease is prevalent in women with prior gestational diabetes mellitus and independently associated with insulin resistance and waist circumference. Diabetes Care. 2017:40:109-16.

9. Kim MH, Kwak SH, Kim SH, Hong JS, Chung HR, Choi SH, Kim MY, Jang HC Pregnancy outcomes of women additionally diagnosed as gestational diabetes by the International Association of the Diabetes and Pregnancy Study Groups Criteria. Diabetes Metab J. 2019;43:766-75.

10. Sapienza AD, Francisco RP, Trindade TC, Zugaib M. Factors predicting the need for insulin therapy in patients with gestational diabetes mellitus. Diabetes Res Clin Pract. 2010;88:81-6.

11. Kim MK, Han K, You SY, Kwon HS, Yoon KH, Lee SH. Prepregnancy smoking and the risk of gestational diabetes requiring insulin therapy. Sci Rep. 2020;10:13901

12. Ko SH, Han K, Lee YH, Noh J, Park CY, Kim DJ, Jung CH, Lee KU, Ko KS. TaskForce Team for the Diabetes Fact Sheet of the Korean Diabetes Association. Past and Current Status of Adult Type 2 Diabetes Mellitus Management in Korea: A National Health Insurance Service Database Analysis. Diabetes Metab J. 2018; 42: 93-100.

13. Kim DH, Nam GE, Han K, Kim YH, Park KY, Hwang HS, Han B, Cho SJ, Jung SJ, Yoon YJ, Roh YK, Cho KH, Park YG. Variabilities in weight and waist circumference and risk of myocardial infarction, stroke, and mortality: a nationwide cohort study. Endocrinol Metab. 2020;35:933-42.

14. Lee $\mathrm{SH}, \mathrm{Han} \mathrm{K}$, Kim HS, Cho JH, Yoon KH, Kim MK. Predicting the development of myocardial infarction in middle-aged adults with type 2 diabetes: a risk model generated from a nationwide population-based cohort study in Korea. Endocrinol Metab. 2020;35:636-46.

15. European Association for the Study of the Liver (EASL); European Association for the Study of Diabetes (EASD); European Association for the Study of Obesity (EASO). EASL-EASD-EASO Clinical Practice Guidelines for the management of non-alcoholic fatty liver disease. J Hepatol 2016; 64: 1388-1402

16. Lee YH, Bang H, Park YM, Bae JC, Lee BW, Kang ES, Cha BS, Lee HC, Balkau $B$, Lee WY, Kim DJ. Non-laboratory-based self-assessment screening score for non-alcoholic fatty liver disease: development, validation and comparison with other scores. PLoS ONE. 2014;9:e107584.

17. Kim MK, Ko SH, Kim BY, Kang ES, Noh J, Kim SK, Park SO, Hur KY, Chon S, Moon MK, Kim NH, Kim SY, Rhee SY, Lee KW, Kim JH, Rhee EJ, Chun S, Yu $\mathrm{SH}$, Kim DJ, Kwon HS, Park KS, Committee of Clinical Practice Guidelines, Korean Diabetes Association. Clinical practice guidelines for type 2 diabetes mellitus in Korea. Diabetes Metab J. 2019;2019(43):398-406.

18. Lee MY, Hyon DS, Huh JH, Kim HK, Han SK, Kim JY, Koh SB. Association between serum gamma-glutamyltransferase and prevalence of metabolic syndrome using data from the Korean genome and epidemiology study. Endocrinol Metab. 2019;34:390-7.

19. Lee SM, Kwak SH, Koo JN, Oh H, Kwon JE, Kim BJ, Kim SM, Kim SY, Kim GM, Joo SK, Koo BK, Shin S, Vixay C, Norwitz ER, Park CW, Jun JK, Kim W, Park JS. Non-alcoholic fatty liver disease in the first trimester and subsequent development of gestational diabetes mellitus. Diabetologia. 2019;62:238-48. 
20. Hagström H, Höijer J, Ludvigsson JF, Bottai M, Ekbom A, Hultcrantz R, Stephansson O, Stokkeland K. Adverse outcomes of pregnancy in women with non-alcoholic fatty liver disease. Liver Int. 2016;36:268-74.

21. Olubamwo OO, Virtanen JK, Pihlajamaki J, Tuomainen TP. Association of fatty liver index with risk of incident type 2 diabetes by metabolic syndrome status in an Eastern Finland male cohort: a prospective study. BMJ Open. 2019:9:e026949.

22. Bedogni G, Bellentani S, Miglioli L, Masutti F, Passalacqua M, Castiglione A, Tiribelli C. The Fatty Liver Index: a simple and accurate predictor of hepatic steatosis in the general population. BMC Gastroenterol. 2006;6:33.

23. Huang $X, X u M$, Chen $Y$, Peng $K$, Huang $Y$, Wang $P$, Ding L, Lin L, Xu Y, Chen $Y$, Lu J, Wang W, Bi Y, Ning G. Validation of the fatty liver index for nonalcoholic fatty liver disease in middle-aged and elderly Chinese. Medicine. 2015;94:e1682

24. Yang BL, Wu WC, Fang KC, Wang YC, Huo TI, Huang YH, Yang HI, Su CW, Lin $\mathrm{HC}$, Lee FY, Wu JC, Lee SD. External validation of fatty liver index for identifying ultrasonographic fatty liver in a large-scale cross-sectional study in Taiwan. PLoS ONE. 2015;10:e0120443.

25. Bril F, Ortiz-Lopez C, Lomonaco R, Orsak B, Freckleton M, Chintapalli K, Hardies J, Lai S, Solano F, Tio F, Cusi K. Clinical value of liver ultrasound for the diagnosis of nonalcoholic fatty liver disease in overweight and obese patients. Liver Int. 2015;35:2139-46.

26. Kim WJ, Chung Y, Park J, Park JY, Han K, Park Y, Park IY, Ko HS. Influences of pregravid liver enzyme levels on the development of gestational diabetes mellitus. Liver Int. 2021;41:743-53.

\section{Publisher's Note}

Springer Nature remains neutral with regard to jurisdictional claims in published maps and institutional affiliations.
Ready to submit your research? Choose BMC and benefit from:

- fast, convenient online submission

- thorough peer review by experienced researchers in your field

- rapid publication on acceptance

- support for research data, including large and complex data types

- gold Open Access which fosters wider collaboration and increased citations

- maximum visibility for your research: over $100 \mathrm{M}$ website views per year

At BMC, research is always in progress.

Learn more biomedcentral.com/submissions 